\title{
Measuring Multidimency Poverty Method
}

\author{
${ }^{1}$ Muhammad Asim and ${ }^{2}$ Huey Fang Pasha \\ ${ }^{1,2}$ University Marketing, Admissions and Communications, Monash University, Malaysia \\ ${ }^{1}$ raphaelfang@monash.edu
}

\author{
Article Info \\ Journal of Journal of Enterprise and Business Intelligence (http://anapub.co.ke/journals/jebi/jebi.html) \\ Doi: https://doi.org/10.53759/5181/JEBI202202005 \\ Received 22 June 2021; Revised form 14 August 2021; Accepted 20 October 2021. \\ Available online 05 January 2022. \\ (C2022 Published by AnaPub Publications.
}

\begin{abstract}
The calculation of the poverty rate in Malaysia is measured based on the Poverty Line Income (PGK). Most recently, in 2019, PGK was reviewed. The reassessment of this measurement is in line with current developments as well as Malaysia's developmenttowards developed countries. But to what extent does the poverty measure using PGK reflect the real state of poverty for a household? To overcome poverty, we need to know who is poor, and in what dimension they are poor.To take these into account, we used the multidimensional poverty index measurement method or Multidimensional Poverty Index (MPI) as one of the alternatives to replace poverty measurement using the income method. This multidimensional poverty measurement is more of a measure to identify "who is poor". Apart from calculating the amount of deficiency experienced by a household, this study also conducts two forms of analysis, namely weightlessMPI analysis and MPI analysis with the same weighting. This study uses primary data obtained from face-to-face interviews on 378 heads of households in Sik District, Kedah, in 2013. Selected respondents are the result of random observations conducted by the National Statistics Department. The findings of the study, when the same weighting value is given for each of the eight dimensions, found that if the poverty line $\mathrm{k} \geq 4$ is set, 34.66 percent or 131 households are poor in various dimensions. Determining the $\mathrm{k} \geq 4$ separationline in this weighted analysis does not mean that households are deficient in four dimensions, but that households are deficient by four and more dimensions. The studyfound that the average poverty (A) is 31.36 percent, which means that, among the poor households (131), on average, they suffer from a deficit of 31.36 percent of the total poverty dimension (22 dimensions). MPI, the adjusted poverty rate (Mo), is 0.1086 , which means that the depth of poor households from the set separation line is 10.86 percent or 11 out of 100 depths or in other words the depth of poverty of households experiencing a deficit from the overall shortfall is 10.86 percent.
\end{abstract}

Keywords - Poverty; Multidimensional Poverty; Multidimensional Poverty Index (MPI); Poverty Line Income (PGK); Kedah, Malaysia.

\section{INTRODUCTION}

Poverty is a situation of deprivation that occurs not on the will and willingness ofpoor households [1]. Poverty measurement in Malaysia has undergone several changes in determining who is poor.Since 1977, Poverty Line Income (PGK) has been used as a method of poverty measurement. However, in 2005, the poverty estimation model using the 1977 Methodologywas reviewed, and the 2005 Methodology was developed. The reassessment of PGK continues to occur. For example, in 2012, the reassessment was made on 2005 [2]. Recently, the new PGK model is used in the Household Income and Basic Amenities Survey Report, (HIS) [3].

The weaknesses of this PGK was discussed by [4]. He argued that this index ignores the distribution of income among the poor. A good index is an index that takes into account welfare functions that are sensitive to income distribution among poor households. Besides, a good poverty index should also be able to give a better picture of poverty and be more convincing to use in formulating policies. Earlier, [5] explained that poverty is more often associated with the financial dimension because this dimension is most easily observed, measured, and compared. Whereas, poverty is also related to various other dimensions, including social, cultural, political science, health, education, religion, and character. [6] explained that the method used to calculate the PGK to estimate the incidence of poverty in Malaysia needs to be reviewed. It is because this method of determining PGK plays an essential role in influencing the poverty profile, which is the key to the formation of poverty eradication policies. If misinterpretations are related to the profile of poverty, then the goal of poverty eradication is difficult to achieve. 
Therefore, to improve the accuracy of identifying poor households, the Malaysian government has reviewed the PGK calculation method[8].

[7] argued that the uses of income data are not a perfect way to measure poverty. The studies of poverty have evolved and cover various dimensions of poverty.The interesting part is that this dimension of poverty exists as a result of interviews with the poor themselves. The definition of poverty has been expanded to include social and psychological burdens as well as daily survival to identify poor communities. The concept of poverty has been reassessed by [9] as a lack of ability to enable one to live well. The assessed indicatorsincluded income, health, education, power, and human rights. [10] proposed a solution with a method that can measure economic performance to prevent poverty through self-efficacy [11].

Thus, this study is in line with the opinion of [12] and [13], where poverty is not just about insufficient income but more than that. The community is said to be able to get out of poverty when the community can improve their capacity and increase their access to various resources, institutions, and support facilities. [2] stated that involvement in entrepreneurial activities could accelerate a person's time frame to get out of poverty. Similarly, farmers involved in non-agricultural activities can increase their total income, which in turn can free them from poverty faster than farmers who are not involved in non-agricultural activities [7] and [2].

In Malaysia, the measurement of poverty is still unidimensional. A person'sincome is used to determinehis/her povertylevel. Poverty measurement using multidimensional methods is not yet widespread and has not been used as a basis for policymakers in poverty eradication. Therefore, the results of this multidimensional poverty study are expected to provide an accurate picture and measurement to those responsible parties and policymakers to achieve the target of reducing poverty more effectively. It is because a good measure of poverty needs to emphasize the aspect of identification. With this multidimensional poverty measurement, the identity or characteristics of a poor person exist on two levels. The first level is to identify individual shortcomings in each dimension, and the second involves the definition of poverty through all dimensions. Multidimensional poverty is a new method of measuring poverty that allows us to see the real shortcomings experienced by a household. This multidimensional poverty approach is essential to provide a more accurate and effective analysis to policy makers.

The results of this study are also expected to provide a new picture of the dimensions of poverty that may be taken into account in the discussion on poverty eradication plans undertaken by Malaysia. The results of the study also allow the approach to reduce poverty to be more directed as a person or an area may have different needs. The directed approach will be more focused on the problem according to specific dimensions of poverty.

Literature Review

Poverty measures based on the PGK are felt to be too narrow and do not reflect actual poverty. Individuals with income under PGK are said to be poor. Does this describe actual poverty? Poverty should be viewed and analyzed from various angles or dimensions so that the interpretation of poverty is more accurate and can explain the actual state of poverty. One of the alternatives to replace the poverty measure using the income method is the multidimensional poverty measure. This multidimensional poverty measurement is more of a measure to identify "who is poor" [2].

It is common knowledge that the poor are a society that needs help so that they can get out of poverty. Therefore, the measure of poverty must be accurate to describe poverty. Thisis because it will provide a clear understanding related to poverty so that the policies that will be formed are believed to be able to solve the problems of poverty faced [14]. In 1997, the Human Development Report and the 2000/1 World Development Report stated that poverty was a multidimensional phenomenon. While the Millennium Declaration and the MDGs began discussing the issue of poverty in multidimensional since 2000.

One of the multidimensional poverty measurement methods is to use the Alkire and Foster Method (AF Method). Poverty measurement using this AF Method contains the poverty dimension, the dimensional separating line to determine who is poor in that dimension, and the poverty separation line is used to determine who is suffering enough to be classified as multidimensionally poor. This method is believed to be able to identify who is poor and, in turn, will be able to solve the problem of poverty faced [15]. [16] have applied the AF Method in their study on Bhutan. The study was conducted in rural and urban areas. Five dimensions have been used, namely income, education, number of available rooms, access to electricity, and drinking water. Two additional dimensions are only 
analyzed in rural areas, namely, access to roads and land ownership.

\section{RESEARCH METHODS}

Apart from calculating the amount of deficiency experienced by a household, this study also conducts two forms of analysis, namelyweightless MPI analysis and weighted MPI analysis. The weights used for weighted MPI analysis are the same. This study uses primary data obtained from face-to-face interviews on 378 household heads in Sik District, Kedah. Selected respondents are the result of a stochastic analysis conducted by the National Statistics Department. This study is a case study, and the selection of Sik is because Sik District is one of the poorest districts in Kedah, the percentage of poor households is 22.13 percent or 3322 households [18]. The characteristics of the desired sample are the residents of Sik District, whether they belong to the poor and non-poor groups.

Apart from that, the number of poor households recorded by the e-sinar system until 20 November 2012 is 22,067 households. Based on the e-sinar, the poor people in Kedah are recorded as follows:

$\begin{array}{ll}\text { i. } & \text { Poorpeople } \\ \text { a. } & \text { Household monthly income }<\text { RM720 } \\ \text { b. } & \text { The income per capita < RM180 } \\ \text { ii. } & \text { The hardcore poor } \\ \text { a. } & \text { Household monthly income }<\text { RM430 } \\ \text { b. } & \text { The income per capita }<\text { RM100 }\end{array}$

The poverty model used contains dimensions and indicators. The dimensions of poverty for the poor are varying. The poverty line for each dimension studied is also different. Among the dimensions that are the focus of this study are basic needs such as food, clothing, and shelter. However, the study also included dimensions that were deemed necessary, as suggested by the researchers in the previous studies.

In this study, the questionnaires used were modified from the questionnaires obtained from the United States Agency, International Development, USAID's Office of Global Health, Household Survey and International Fund for Agricultural Development (IFAD) and according to the methods specified by [19]). Here are eight (20) dimensions, including income dimension and twenty-two (21) indicators that will be used in MPI calculations that are considered important by researchers based on reading and scenarios as well as the reality of poverty in Malaysia, as shown in table 1 .

Table 1. Dimensions and Indicators of the Study

\begin{tabular}{llcl}
\hline Dimension & Indicator & \\
\hline 1. & Income & i. & Salaries, grants, donations \\
\hline 2. & Food & i. & Frequency of daily food intake \\
& & ii. & Adequacy of food taken \\
\hline 3. & Home features & i. & Floor \\
& & ii. & Wall \\
& & iii. & Roof \\
& & iv. & Toilets \\
& & v. & Number of bedrooms \\
\hline 4. & Clothes & i. & Frequency of clothing purchases per year \\
\hline 5. & Asset Ownership & i. & Ownership of assets or property \\
\hline 6. & Education & i. & Head of household education level \\
& & ii. & KIR literacy \\
& & iii. & Children's school year \\
& & iv. & School-age children \\
& & v. & Educational opportunities for eligible households \\
& & i. & (SPM graduates) \\
\hline 7. & Health & & illness \\
& & & \\
\hline
\end{tabular}




\begin{tabular}{lll} 
& ii. & Acquired health facilities \\
\hline 8. Standard of living /Welfare & i. & Home ownership status \\
& ii. & Electricity \\
iii. & Water and water quality \\
& iv. & Fuel (main fuel for cooking) \\
& v. & $\begin{array}{l}\text { Home furnishings (TV, refrigerator, washing } \\
\text { machine, telephone, fan) }\end{array}$ \\
\hline
\end{tabular}

Below is a brief list of 12 steps on how this Alkire and Foster (AF) method forms the Multidimensional Poverty Index (MPI).The steps are described in non-mathematical sentence form as follows:

Step 1: Select the analysis unit.

Step 2: Select a dimension.

Step 3: Select an indicator.

Step 4: Define poverty lines for each dimension.

Step 5: Using the poverty line, that is, to replace a person's achievement with his status associated with the poverty line.

Step 6: Calculate the total deficit for each household.

Step 7: Set a second poverty line. The second poverty line, $\mathrm{k}$, stipulates that a person's total dimensions should be less to allow him to be categorized as multidimensionally poor.

Step 8: Use the poverty line, $\mathrm{k}$, to get a set of poor people and censor the nonpoor people.

Step 9: Calculate the poverty rate (headcount ratio), H. Divide the number of poor individuals by the sum of all individuals.

Step 10: Calculate the average poverty gap, A, which is the average number of shortcomings faced by the poor. It is calculated by summing the ratio of deficiencies faced by each poor person and divided by the number of poor people.

Step 11: Calculate the adjusted poverty rate (adjusted headcount ratio), $\mathrm{M}_{\mathrm{o}}$, which can be obtained by multiplying $\mathrm{H}$ by A.

Step 12: Separation by a group and by dimension. Adjusted poverty rates, $\mathbf{M}_{\mathrm{o}}$ can be separated by sub-groups such as by religion, urban/rural, and racial.

Profile of the Study

\section{FINDINGSOF THE STUDY}

The study found that in general, the average age of the head of the household (KIR)is 54.3 years, while the minimum age is 21 , and the maximum age is 88 . The majority of respondents were Malay Muslims, which is 89.2 percent (337). While 9.5 percents are Siamese, and the remaining 1.3 percent are Chinese. A total of 314 people (83.1\%) of the total respondents were men as heads of families or heads of households. But there are also some cases (16.9\%) of women who are the head of the household. This is because they have lost their husbands, have separated from their husbands, or remain single without getting married.

Next of the total heads of households, a total of 291 people (77.0\%) were married. The remaining 20.1 percent are single parents, while another 2.9 percent are unmarried household heads. In terms of education, almost one third $(30.7 \%)$ of household heads have attended school at least at the primary school level. However, some KIRs have never been to school (15.1\%), as shown in table 2 .

Table 2. Head of Household Education Level

\begin{tabular}{lcc}
\hline \multicolumn{1}{c}{ Education Level } & Number & Percentage \\
\hline Did not go to school & 57 & 15.1 \\
Primary school (Year 1-3) & 34 & 9.0 \\
Primary school (Year 4-6) & 82 & 21.7 \\
Secondary school (Form 1-3) & 51 & 13.5 \\
Secondary school (Vocational / Technical) & 2 & 0.5
\end{tabular}


Secondary school (Form 4-5)

135

3

3

10

1
35.7

0.8

0.8

2.6

0.3

Source: Questionnaire 2013

In addition to information on KIR's highest level of education, information related to reading and writing abilities was also asked to KIRs. Of the $378 \mathrm{KIRs}$, a total of $64 \mathrm{KIRs}$, which is 16.9 percent could not read and write.

KIR's main occupation is rubber tappers, which is almost half $(45.8 \%)$ of the source of livelihood from the activity. Other economic activities such as business (6.6\%), truck drivers (2.6\%), teachers (1.9\%), security guards $(1.6 \%)$, and so on. However, there are also KIR who do not work, which is a total of 66 people (17.5\%). The main reasons for KIR not working are pain, and among the types of diseases recorded are high blood pressure, stroke, old age, paralysis, diabetes, heart disease, and so on. For the survival of KIR, who do not work depends on their children and wives, siblings, assistance from the Social Welfare Department, zakat assistance, pensions, and some who get neighbours' contributions. In addition to having a primary job, a small percentage (9.6\%) of KIRs have side jobs. Among the KIR side jobs such as repairing electrical goods, Quran teachers, selling cakes, cutting clumps, raising livestock, and so on. From these economic activities, KIR has earned a certain amount of monthly income. Based on this monthly income, the study has classified respondents into several categories of poverty, including hardcore poor (RM0-RM580), poor (RM581-RM940), vulnerable (RM941-RM3860) and non-poor (RM3861 and above). A summary of the percentage of this type of poverty is recorded in Figure 1.

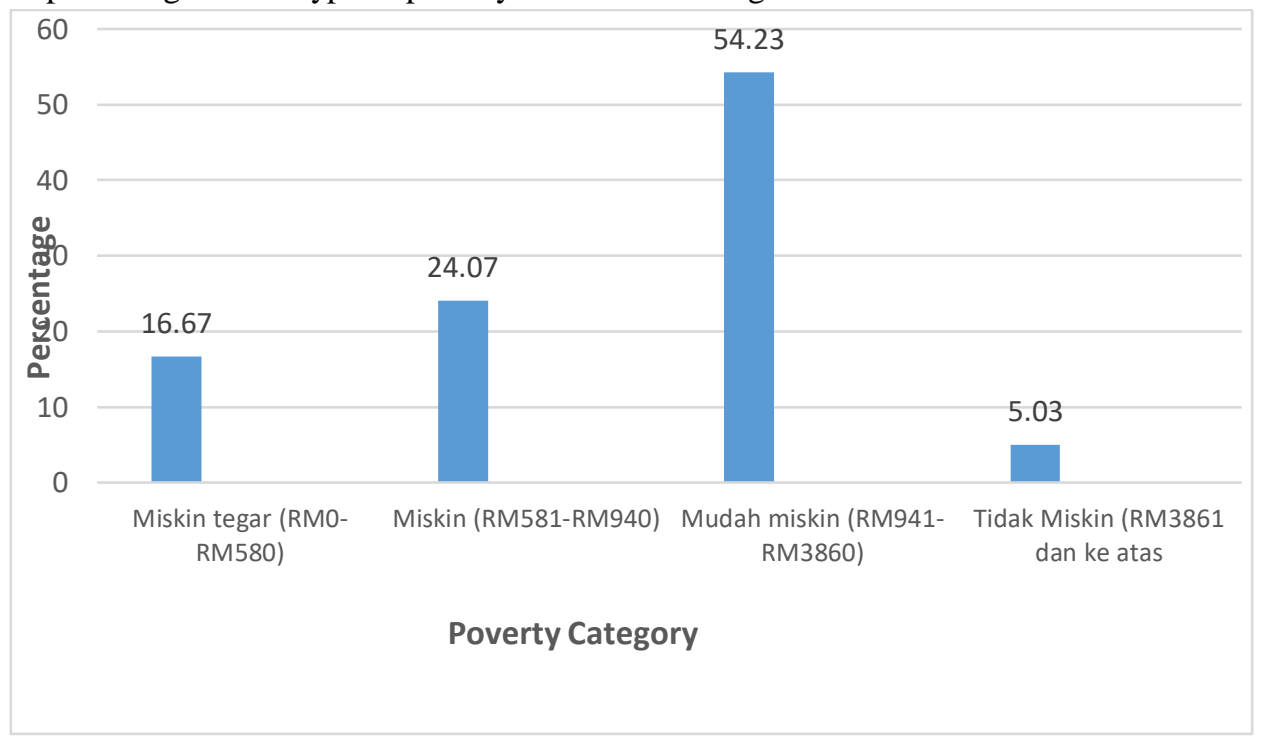

Fig 1. Poverty Category

This simple classification of the poor refers to the interpretation of the lowest $40 \%$ income group (B40 group) or those households with a monthly income of less than RM3860 per month.

\section{Total Deficiency for Each Dimension}

Preliminary analysis has been doneto look at the shortcomings faced by households. Table 3 shows the percentage of deficiencies experienced by households for each indicator studied. The study found that 51.05 percent of households had a deficiency in bedroom indicators. Of this value, 3.2 percent (12) of households do not have a bedroom. While another 9.3 percent have one bedroom, and the remaining 38.6 percent of households only have two bedrooms. The setting of the three bedrooms is used as a cut off to distinguish between deficient households and those that do not have deficiencies in the bedroom indicator. 
The second highest indicator of shortage experienced by households is the status of home ownership. Forty percent or 153 households do not own their own home and land. Besides, households are also experiencing shortages in income indicators (40.74\%), frequency of purchase of clothing per year (24.34\%), low level of education of family heads that are at least finishing primary school (32.80\%) and some household members are disabled or chronic pain $(25.66 \%)$.

Households are also experiencing shortages in the frequency of food intake per day (1.06\%) and adequacy of food taken $(3.17 \%)$. While indicators in the home featuredimension that apart from the number of bedrooms recorded a shortage of less than 10 percent. The percentage deficiency of indicators in the education dimension is also less than 10 percent except for the head of householdseducation level. As for the electricity supply indicator, the whole household is not in short supply. Every household gets electricity supply from Tenaga Nasional Berhad (TNB).

Table 3. Percentage of Household Suffering for each Indicator

\begin{tabular}{|c|c|c|c|c|}
\hline Dimension & & Indicator & $\begin{array}{c}\text { Total } \\
\text { Deficiency }\end{array}$ & $\begin{array}{l}\text { Percentage of } \\
\text { Deficiency }\end{array}$ \\
\hline 1. Income & i. & Salaries, grants, donations & 154 & 40.74 \\
\hline 2. Food & $\begin{array}{l}\text { i. } \\
\text { ii. }\end{array}$ & $\begin{array}{l}\text { Frequency of daily food intake } \\
\text { Adequacy of food taken }\end{array}$ & $\begin{array}{c}4 \\
12\end{array}$ & $\begin{array}{l}1.06 \\
3.17\end{array}$ \\
\hline 3. Home features & $\begin{array}{l}\text { i. } \\
\text { ii. } \\
\text { iii. } \\
\text { iv. } \\
\text { v. }\end{array}$ & $\begin{array}{l}\text { Floor } \\
\text { Wall } \\
\text { Roof } \\
\text { Toilets } \\
\text { Number of bedrooms }\end{array}$ & $\begin{array}{c}8 \\
36 \\
4 \\
1 \\
193\end{array}$ & $\begin{array}{c}2.12 \\
9.52 \\
1.06 \\
0.26 \\
51.05\end{array}$ \\
\hline 4. Clothes & i. & Frequency of clothing purchases per year & 92 & 24.34 \\
\hline 5.Asset ownership & i. & Ownership of assets or property & 38 & 10.05 \\
\hline 6. Education & $\begin{array}{l}\text { i. } \\
\text { ii. } \\
\text { iii. } \\
\text { iv. } \\
\text { v. }\end{array}$ & $\begin{array}{l}\text { Head of household education level } \\
\text { KIR literacy } \\
\text { Children's school year } \\
\text { School-age children } \\
\text { Educational opportunities for eligible } \\
\text { households (SPM graduates) }\end{array}$ & $\begin{array}{c}124 \\
17 \\
8 \\
\\
17 \\
17\end{array}$ & $\begin{array}{r}32.80 \\
4.50 \\
2.12 \\
4.50 \\
4.50\end{array}$ \\
\hline 7. Health & ii. & $\begin{array}{l}\text { Household members with disabilities or } \\
\text { chronic illness } \\
\text { Acquired health facilities }\end{array}$ & $\begin{array}{l}97 \\
38\end{array}$ & $\begin{array}{l}25.66 \\
10.05\end{array}$ \\
\hline $\begin{array}{l}\text { 8. Standard of } \\
\text { living / Welfare }\end{array}$ & $\begin{array}{l}\text { i. } \\
\text { ii. } \\
\text { iii. } \\
\text { iv. } \\
\text { v. }\end{array}$ & $\begin{array}{l}\text { Home ownership status } \\
\text { Electricity } \\
\text { Water and water quality } \\
\text { Fuel (main fuel for cooking) } \\
\text { Home furnishings (TV, refrigerator, } \\
\text { washing machine, telephone, fan) }\end{array}$ & $\begin{array}{c}153 \\
0 \\
4 \\
\\
2 \\
11\end{array}$ & $\begin{array}{c}40 \\
0 \\
1.06 \\
0.53 \\
2.91\end{array}$ \\
\hline
\end{tabular}

Source: Findings of the Study

Figure 2 shows the deficiencies experienced by households in the form of percentages. It was found that 12.43 percent of households did not experience any deficiencies. While deficiencies in the six, seven, eight, ten, and 
fourteen indicators were less than five percent. Most households were found to be deficient in two indicators of 24.34 percent, followed by one and three indicators of 20.37 percent and 14.02 percent, respectively.

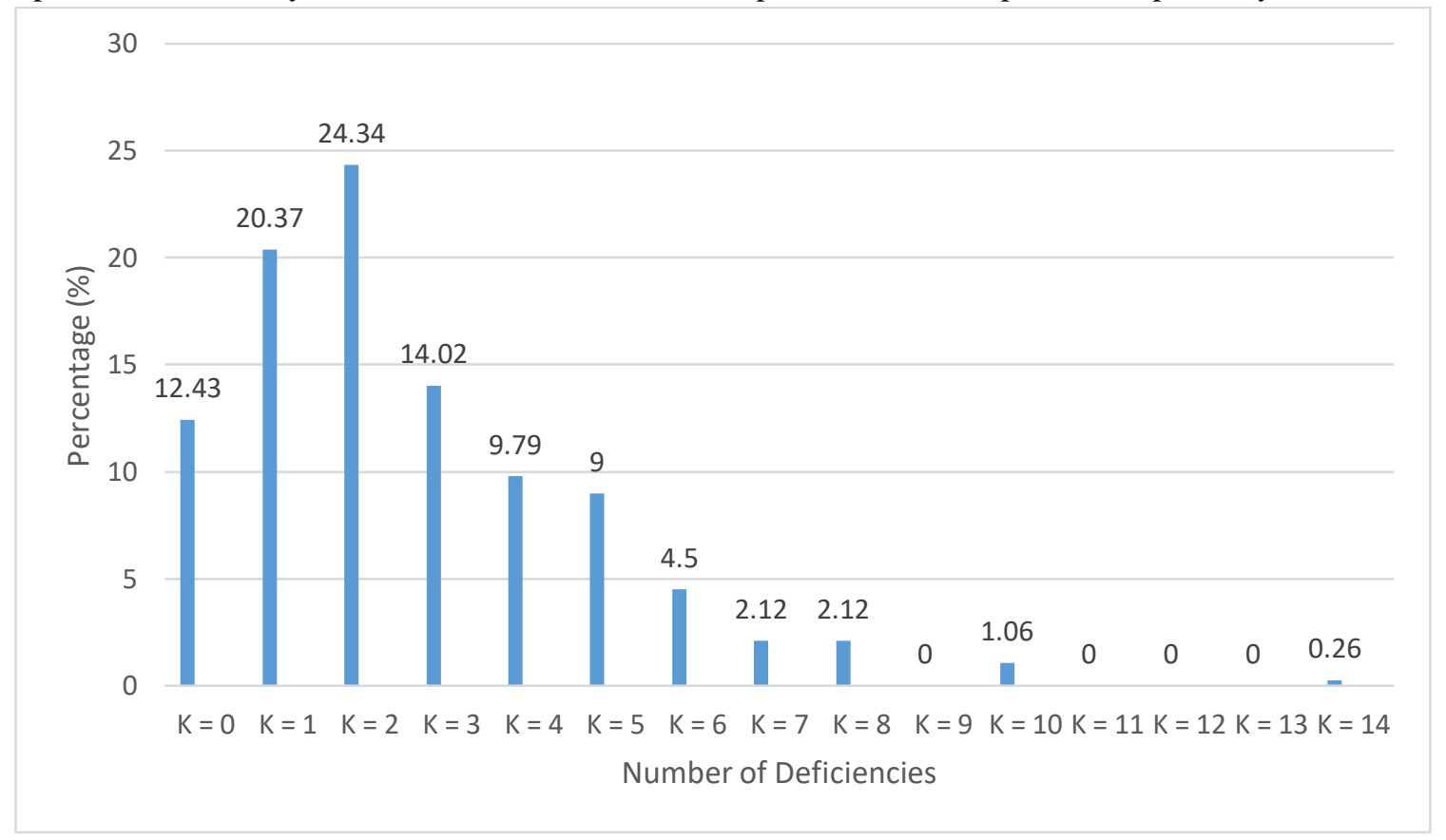

Source: Findings of the Study

Fig 2. Percentage of Households Suffering in the Poverty Dimension

The previous description of Table 3 only describesthe shortcomings in terms of dimensions or indicators experienced by households. While Figure 2 only represents the percentage of shortcomings in the number of indicators. These situationsare not enough to classify or declare a household that is categorized as poor in various dimensions. For this purpose, an aggregate separating line must be obtained. This separating line refers to the minimum number of indicators that must be met before a household can be categorized as poor. This separating line is also known as the poverty line.

The determination of this poverty line (k) allows the household to be determined as poor in various dimensions or not. For example, if $\mathrm{k} \geq 4$ is defined as an aggregate separating line, then a household needs to experience a deficiency in four or more indicators before the household is categorized as multidimensionally poor. The poverty line determination is according to the Alkire\& Foster (AF) method. According to this AF method, the determination of the poverty line is based on the consideration of the value of the researcher. This is because this AF method is just a general framework in the measurement of multidimensional poverty. Therefore, the dimensions and separating lines in each study made may vary according to suitability [22].

Weightless Multidimensional Poverty Estimation

As shown in Table 4, if $\mathrm{k} \geq 4$ is defined as the poverty line, then 28.84 per cent or 109 households are declared poor in various dimensions. Meanwhile, if $\mathrm{k} \geq 5$ is defined as the poverty line, then 19.05 percent of households are declared as poor in various dimensions. It can be observed that the higher the value of the poverty line, the number of poor households will decrease and vice versa.The less the value of the poverty line, the higher the number of households categorized as poor in various dimensions.

The average poverty (A) shown by column four in Table 4, describes the percentage of overall poverty among poor households. At $\mathrm{k} \geq 4$, the average poverty was 24.77 percent. This means that, among the poor households (109 households), on average, they suffer from a deficit of 24.77 percent of the total poverty dimension (22 dimensions). The average poverty will increase as the defined poverty line increases.

Column five shows the Multidimensional Poverty Index $\left(\mathrm{M}_{0}\right)$ in various levels of the poverty line, which is calculated to find out the depth of poverty faced by households. For example, if the poverty line is set at $\mathrm{k} \geq 4$, the poverty depth rate is 0.0714 . This explains the poverty rate for every poor household, which is 7.1 percent. The 
poverty rate will decrease as the poverty line increases. This shows that the number of households in poverty is decreasing as the deficit separating line is raised. Usually, households only suffer from shortcomings in three, four and five indicators. Only one household suffers from 14 indicators.

Table 4. WeightlessMultidimensional Poverty Estimation (MPI)

\begin{tabular}{|c|c|c|c|c|}
\hline $\begin{array}{c}\text { Aggregate } \\
\text { Separation Point }(\mathrm{k})\end{array}$ & $\begin{array}{c}\text { Number of Poor } \\
\text { Households }\end{array}$ & $\begin{array}{c}\text { Poverty Rate } \\
(\mathrm{H})\end{array}$ & $\begin{array}{c}\text { Average } \\
\text { Poverty (A) }\end{array}$ & $\begin{array}{c}\text { Adjusted Poverty } \\
\text { Rate }\left(\mathrm{M}_{0}\right) \mathrm{MPI}\end{array}$ \\
\hline$\geq 2$ & 254 & 0.6719 & 0.1677 & 0.1127 \\
\hline$\geq 3$ & 162 & 0.4286 & 0.2113 & 0.0905 \\
\hline$\geq 4$ & 109 & 0.2884 & 0.2477 & 0.0714 \\
\hline$\geq 5$ & 72 & 0.1905 & 0.2816 & 0.0536 \\
\hline$\geq 6$ & 38 & 0.1005 & 0.3301 & 0.0332 \\
\hline$\geq 7$ & 21 & 0.0556 & 0.3766 & 0.0209 \\
\hline$\geq 8$ & 13 & 0.0344 & 0.4126 & 0.0142 \\
\hline$\geq 9,10$ & 5 & 0.0132 & 0.4909 & 0.0065 \\
\hline$\geq 11,12,13,14$ & 1 & 0.0026 & 0.6364 & 0.0017 \\
\hline
\end{tabular}

Source: Findings of the Study

In short, the findings of this study using the AF method can meet the basic needs because the results of three (3) measures that are indicators of poverty can be known, namely the measure of poverty incidence $(\mathrm{H})$, the measure of poverty gap (A) and the measure of poverty severity $\left(\mathrm{M}_{0}\right)$.

\section{Poverty Estimation}

\section{Multidimensional with Equal Weights}

This study has set the same weight on all dimensions. Table 5 shows the same weighting values given to each dimension (1/8 or 0.125$)$. This same weighting value means that each dimension is assumed to have equal importance in resulting in poverty [5].

Table 5. Same Weightingfor Each Dimension

\begin{tabular}{|c|c|c|c|}
\hline Dimension & Indicator & & Weighting \\
\hline 1. Income $(1 / 8)$ & i. & Salaries, grants, donations & $1 / 8$ \\
\hline 2. Food (1/8) & $\begin{array}{l}\text { i. } \\
\text { ii. }\end{array}$ & $\begin{array}{l}\text { Frequency of daily food intake } \\
\text { Adequacy of food taken }\end{array}$ & $\begin{array}{l}1 / 16 \\
1 / 16\end{array}$ \\
\hline 3. Home features $(1 / 8)$ & $\begin{array}{l}\text { i. } \\
\text { ii. } \\
\text { iii. } \\
\text { iv. } \\
\text { v. }\end{array}$ & $\begin{array}{l}\text { Floor } \\
\text { Wall } \\
\text { Roof } \\
\text { Toilets } \\
\text { Number of bedrooms }\end{array}$ & $\begin{array}{l}1 / 40 \\
1 / 40 \\
1 / 40 \\
1 / 40 \\
1 / 40\end{array}$ \\
\hline 4. Clothes (1/8) & i. & Frequency of clothing purchases per year & $1 / 8$ \\
\hline 5.Asset ownership (1/8) & i. & Ownership of assets or property & $1 / 8$ \\
\hline 6. Education (1/8) & $\begin{array}{l}\text { i. } \\
\text { ii. } \\
\text { iii. } \\
\text { iv. } \\
\text { v. }\end{array}$ & $\begin{array}{l}\text { Head of household education level } \\
\text { KIR literacy } \\
\text { Children's school year } \\
\text { School-age children } \\
\text { Educational opportunities for eligible households } \\
\text { (SPM graduates) }\end{array}$ & $\begin{array}{l}1 / 40 \\
1 / 40 \\
1 / 40 \\
1 / 40 \\
1 / 40\end{array}$ \\
\hline
\end{tabular}




\begin{tabular}{|l|cl|c|}
\hline 7. Health (1/8) & i. & $\begin{array}{l}\text { Household members with disabilities or chronic } \\
\text { illness } \\
\text { Acquired health facilities }\end{array}$ & $1 / 16$ \\
& ii. & Home ownership status & $1 / 16$ \\
\hline 8. Standard of living/ & i. & Hectricity & $1 / 40$ \\
Welfare (1/8) & ii. & Elen & $1 / 40$ \\
& iii. & Water and water quality & $1 / 40$ \\
& iv. & Fuel (main fuel for cooking) & Home furnishings (TV, refrigerator, washing \\
& v. & $1 / 40$ \\
\hline
\end{tabular}

Table 6 is the findings of the study when the same weighting values are given for each of the eight dimensions. If the poverty line $\mathrm{k} \geq 4$ is set, 34.66 percent or 131 households are poor in various dimensions. Determining the $\mathrm{k} \geq 4$ separating line in this weighted analysis does not mean that households are deficient in four dimensions, but that households are deficient by four and more dimensions. The average poverty (A) is 31.36 percent. This means that, among the poor households (131), on average, they suffer from a deficit of 31.36 percent of the total poverty dimension (22 dimensions).

While MPI, the adjusted poverty rate (Mo) is 0.1086 . This explains the depth of poverty the household suffers from the overall shortage is 10.86 percent. Mo is a summary of information on poverty rates, average poverty and the severity of poverty. If poor households experience an increase in the deficit in a dimension, the value of Mo will increase greater than the increase in deficit experienced by the household [5]. This proved that the measure of multidimensional poverty (Mo) meets the criteria of monotonicity axiom which is to explain the depth of poverty and consider the aspect of the income distribution of the poor [24] and transfer axiom that the value of Mo index will increase as headcount index increases. Next, the value of Mo is sensitive to inequality among poor households because its emphasis is on the shortcomings experienced by poor households. This advantage is in line with the explanation [23], who asserted that a good index to measure poverty is a measure of poverty should be able to show income distribution among the poor.

Table 6. Multidimensional Poverty Estimation (MPI) using Equal Weights

\begin{tabular}{|c|c|c|c|c|}
\hline $\begin{array}{c}\text { Aggregate } \\
\text { Separation Point }(\mathrm{k})\end{array}$ & $\begin{array}{c}\text { Number of Poor } \\
\text { Households }\end{array}$ & Poverty Rate $(\mathrm{H})$ & $\begin{array}{c}\text { Average Poverty } \\
(\mathrm{A})\end{array}$ & $\begin{array}{c}\text { Adjusted Poverty } \\
\text { Rate }\left(\mathrm{M}_{0}\right) \mathrm{MPI}\end{array}$ \\
\hline$\geq 2$ & 202 & 0.5344 & 0.2564 & 0.1370 \\
\hline$\geq 3$ & 181 & 0.4789 & 0.2722 & 0.1304 \\
\hline$\geq 4$ & 131 & 0.3466 & 0.3136 & 0.1086 \\
\hline$\geq 5$ & 97 & 0.2567 & 0.3523 & 0.0904 \\
\hline$\geq 6$ & 73 & 0.1931 & 0.3868 & 0.0747 \\
\hline$\geq 7$ & 54 & 0.1429 & 0.4208 & 0.0601 \\
\hline$\geq 8$ & 35 & 0.0926 & 0.4617 & 0.0428 \\
\hline$\geq 9$ & 26 & 0.0688 & 0.4879 & 0.0335 \\
\hline$\geq 10$ & 13 & 0.0344 & 0.5442 & 0.0187 \\
\hline$\geq 11$ & 9 & 0.0238 & 0.575 & 0.0136 \\
\hline$\geq 12$ & 5 & 0.0132 & 0.6125 & 0.0081 \\
\hline$\geq 13$ & 1 & 0.0026 & 1.35 & 0.0035 \\
\hline
\end{tabular}

Source: Findings of the Study

\section{CONCLUSION}

A slightly different alternative to existing poverty measurement methods has been applied in identifying poor households. This measurement method is known as the Multidimensional Poverty Index, which uses the AF (Alkarie and Foster) method. The primary basis of this method is to take into account the elements of value consideration 
appropriate to the environmental conditions of the study area. This is because every country, state, district and place are different due to customs, cultural and socioeconomic gaps. Besides, the measurement of this AF method can be modified depending on the purpose of the research. Each indicator used can be reduced or added. Similarly, the importance of each indicator can also be given the appropriate value or weight.

In this article, the Multidimensional Poverty Index (MPI) reports poverty conditions based on deficiencies in the indicators listed. The indicators listed in this study are income, food, household characteristics, clothing, asset ownership, education, health, and standard of living. The use of these indicators allows the poverty rate not only to be calculated in terms of shortcomings in income alone but also shortcomings that occur in other selected indicators. The selection of this indicator is based on the researchers'values as a result of reading and observation of the reality of poverty faced by the community in the study area. Inevitably, observation is a significant contributor to the selection of these indicators. This is because the reality and poverty situation in one place may differ from one place to another. Only someone who has experienced and is in a state of poverty can accurately describe the poverty scenario. This is in accordance with the phrase "Poverty is Subjective". Therefore, the measurement of MPI, which takes into account many of these indicators is considered more appropriate to translate the state of poverty in an area as well as among households or individuals. This analysis also allows for possible assistance to be given to the needy, and the poor will be more targeted. This can reduce leakage, and the government can also spend according to the needs of the poor.

\section{References}

[1]. R. A. Garrido and F. Allendes, "Modeling the Internal Transport System in a Containerport," Transportation Research Record: Journal of the Transportation Research Board, vol. 1782, no. 1, pp. 84-91, Jan. 2002.

[2]. Z.-C. Li, W. H. K. Lam, and S. C. Wong, "Modeling intermodal equilibrium for bimodal transportation system design problems in a linear monocentric city," Transportation Research Part B: Methodological, vol. 46, no. 1, pp. 30-49, Jan. 2012.

[3]. R. Saha, M. T. Tariq, M. Hadi, and Y. Xiao, "Pattern Recognition Using Clustering Analysis to Support Transportation System Management, Operations, and Modeling,” Journal of Advanced Transportation, vol. 2019, pp. 1-12, Dec. 2019.

[4]. A.Thomas B, “'Application of Queuing Theory to Larfarge Cement Transportation System for Truck/Loader Optimazation,"” Aspects in Mining \& Mineral Science, vol. 2, no. 1, Jun. 2018.

[5]. P. Haluzová, "Effective Data Mining for a Transportation Information System," Acta Polytechnica, vol. 48, no. 1, Jan. 2008.

[6]. Z. H. Li and W. Guan, "A Transportation Guidance System Based on Data Mining and GABP," Applied Mechanics and Materials, vol. 490-491, pp. 914-919, Jan. 2014.

[7]. H. M. O. Mokhtar, "HITS: A History-Based Intelligent Transportation System," International Journal of Data Mining \& Knowledge Management Process, vol. 1, no. 2, pp. 34-46, Mar. 2011.

[8]. S. Das, X. Sun, and A. Dutta, "Text Mining and Topic Modeling of Compendiums of Papers from Transportation Research Board Annual Meetings," Transportation Research Record: Journal of the Transportation Research Board, vol. 2552, no. 1, pp. 48-56, Jan. 2016.

[9]. J.-P. Lebacque and M. M. Khoshyaran, "Multimodal Transportation Network Modeling Based on the Generic Second Order Modeling Approach," Transportation Research Record: Journal of the Transportation Research Board, vol. 2672, no. 48, pp. 93103, Oct. 2018

[10]. A.Xie, J. Lu, and E. Parkany, "Work Travel Mode Choice Modeling with Data Mining: Decision Trees and Neural Networks," Transportation Research Record: Journal of the Transportation Research Board, vol. 1854, no. 1, pp. 50-61, Jan. 2003.

[11]. J.-H. Lewe, L. F. Hivin, and D. N. Mavris, "A multi-paradigm approach to system dynamics modeling of intercity transportation," Transportation Research Part E: Logistics and Transportation Review, vol. 71, pp. 188-202, Nov. 2014.

[12]. M. Rahimi, M. Amirgholy, and E. J. Gonzales, "System modeling of demand responsive transportation services: Evaluating cost efficiency of service and coordinated taxi usage," Transportation Research Part E: Logistics and Transportation Review, vol. 112, pp. 66-83, Apr. 2018.

[13]. M. Rahimi, M. Amirgholy, and E. J. Gonzales, "System modeling of demand responsive transportation services: Evaluating cost efficiency of service and coordinated taxi usage," Transportation Research Part E: Logistics and Transportation Review, vol. 112, pp. 66-83, Apr. 2018.

[14]. B. Ran, P. J. Jin, D. Boyce, T. Z. Qiu, and Y. Cheng, "Perspectives on Future Transportation Research: Impact of Intelligent Transportation System Technologies on Next-Generation Transportation Modeling," Journal of Intelligent Transportation Systems, vol. 16 , no. 4, pp. 226-242, Jul. 2012.

[15]. S. Gokul R. and G. Vikas R., "Multitask TSK Fuzzy System Modeling by Mining Intertask Common Hidden Structure," International Journal Of Engineering And Computer Science, Jun. 2016.

[16]. F. Deflorio and L. Castello, "Traffic Modeling of a Cooperative Charge while Driving System in a Freight Transport Scenario," Transportation Research Procedia, vol. 6, pp. 325-350, 2015.

[17]. Z. TIAN, "Modeling and Implementation of an Integrated Ramp Metering-Diamond Interchange Control System," Journal of Transportation Systems Engineering and Information Technology, vol. 7, no. 1, pp. 61-69, Feb. 2007.

[18]. M. L. TAM and W. H. K. LAM, "Modeling the Market Penetration of Personal Public Transport Information System in Hong Kong," Journal of Intelligent Transportation Systems, vol. 9, no. 2, pp. 81-89, Apr. 2005.

[19]. A.Mohammadian and E. J. Miller, "Estimating Expected Price of Vehicles in a Transportation Microsimulation Modeling System," Journal of Transportation Engineering, vol. 128, no. 6, pp. 537-541, Nov. 2002. 
[20]. S. H. Cheon, C. Lee, and S. Shin, "Data-driven stochastic transit assignment modeling using an automatic fare collection system," Transportation Research Part C: Emerging Technologies, vol. 98, pp. 239-254, Jan. 2019.

[21]. X. (Jeff) Ban, L. Chu, R. Herring, and J. D. Margulici, "Sequential Modeling Framework for Optimal Sensor Placement for Multiple Intelligent Transportation System Applications," Journal of Transportation Engineering, vol. 137, no. 2, pp. 112-120, Feb. 2011.

[22]. X. Yang and W. W. Recker, "Modeling Dynamic Vehicle Navigation in a Self-Organizing, Peer-to-Peer, Distributed Traffic Information System," Journal of Intelligent Transportation Systems, vol. 10, no. 4, pp. 185-204, Dec. 2006.

[23]. T. A. Raianov, "Mathematical modeling of a strain gauge measurement system in MATLAB SIMULINK program," Transportation Systems and Technology, vol. 6, no. 2, pp. 85-93, Jun. 2020.

[24]. H. Fricke, M. Schlosser, M. A. Garcia, and M. Kaliske, "Embedding aircraft system modeling to ATM safety assessment techniques," Transportation Research Interdisciplinary Perspectives, vol. 3, p. 100026, Dec. 2019. 